\title{
Filosofia da experiência e formação humana para John Dewey
}

\author{
Darcísio Natal Muraro*
}

\begin{abstract}
Resumo
O objetivo deste trabalho é investigar a concepção de filosofia e sua relação com a formação humana no pensamento de John Dewey. O trabalho visou à análise dos conceitos nas principais obras do autor e seus intérpretes, analisando a reconstrução da filosofia como filosofia da experiência ancorada no método genético, experimental, reflexivo, crítico e criativo. A filosofia da experiência se contrapõe aos dualismos e às filosofias expectadoras do conhecimento, que mantêm a divisão social em classes. $\mathrm{O}$ papel da filosofia da experiência é o de racionalizar pela investigação as possibilidades da experiência humana por meio da reconstrução crítica dos significados. A filosofia da experiência é condição de possibilidade para a vida democrática e para uma educação pautada pela liberdade e emancipação humanas.
\end{abstract}

Palavras-chave: Filosofia. Formação humana. John Dewey.

\footnotetext{
* Doutor em Educação pela Universidade de São Paulo (USP). Professor do departamento de Educação da Universidade Estadual de Londrina (UEL).
} 
O objetivo deste trabalho é analisar a concepção de filosofia da experiência de John Dewey como um modo de pensar a formação humana. Como trabalho conceitual, analisaremos como o autor problematiza a tarefa da filosofia e da educação e nos coloca a perspectiva de reconstrução criativa destes temas centrais do contínuo fazer humano. O trabalho se desenvolve a partir da leitura dos principais trabalhos deste pensador para compreender os argumentos expostos que compõem sua construção teórica. Recorremos também à leitura de alguns de seus intérpretes buscando compreender os argumentos expostos e, assim, elaborar hipóteses que possam contribuir para pensar estes conceitos no contexto atual.

\section{A experiência de filosofar}

Neste primeiro momento, buscaremos compreender como Dewey se coloca o problema do fazer filosófico criando uma base para sua própria formação. Vamos à obra Studies in Logical Theory, publicada em 1903 e ampliada sob o título de Essays in experimental logic em 1916, na qual ele explicitou seu princípio fundamental ou o modus operandi da experiência reflexiva ou pensamento reflexivo, instaurando uma base para construir sua filosofia da seguinte forma: "É necessário trabalhar retrocedendo e avançando no meio dos mais amplos e mais estreitos campos, transformando todo conhecimento obtido por um lado em método de trabalho sobre o outro e, desse modo, testá-lo" (DEWEY, 1953, p. 103). De uma forma mais explícita, Dewey formulou este modus operandi de toda experiência reflexiva formadora da seguinte forma: "É infinito esse processo em espiral: matéria desconhecida a transformar-se, pelo pensamento, em possessão familiar; possessão familiar a instituirse em recursos para julgar e assimilar outra matéria desconhecida.” (DEWEY, 1979a, p. 285-286).

Para Dewey, o problema basilar consiste em compreender o lócus do pensar na experiência humana problemática, conflitiva e em contínua mudança. Ele questionou o pressuposto das teorias lógicas formadas por concepções que determinam previamente as próprias conclusões, diante das quais se faz necessário o trabalho da crítica: "Nossas conclusões são assim controladas pelas próprias noções que necessitam de crítica e revisão" (DEWEY, 1953, p. 107). Desta forma, ele explicitou uma das tarefas da filosofia em relação ao processo do pensamento reflexivo: "[...] um dos objetivos da teoria lógica é precisamente nos fazer criticamente conscientes da significância e influência destas várias distinções, mudá-las de pressupostos prontos por concepções controladas” (DEWEY, 1953, p. 106). O próprio pensar necessita ser submetido ao crivo da reflexão. Dewey iniciou esta discussão nas obras já citadas e continuou o desenvolvimento desta análise na obra Como Pensamos, publicada em 1910 e 
revisada em 1933, sistematizou sua teoria na obra intitulada Lógica. Teoria da inquirição, publicada em 1938. Um dos aspectos do trabalho filosófico de Dewey nestas obras consiste na análise lógica da investigação, ou a investigação da investigação, ou, ainda, a investigação de como pensamos. Ele justificou a necessidade de filosofar sobre o pensamento reflexivo: "Nós não sabemos qual o sentido há de se assinar à expressão 'pensamento reflexivo', exceto em termos do que é descoberto pela investigação da investigação.” (DEWEY, 1960, p. 21). Assim, Dewey desloca a reflexão filosófica da investigação da lógica do conhecimento para a lógica do pensar reflexivo a partir da experiência problemática. Ele leva sua discussão filosófica acerca do pensar para o campo do método experimental. Para ele, tanto racionalismo quanto empirismo têm pressupostos problemáticos por se guiarem pelo dualismo razão e experiência, teoria e prática, concepção e percepção, cada um valorizando respectivamente um polo desta relação. O método experimental se apresentava como caminho promissor para investigar os diferentes aspectos filosóficos da experiência: lógico (tratado como epistemológico), ético, político, estético, antropológico, educacional, religioso. Sobre o método experimental adotado por Dewey, Ratner esclareceu:

[...] este processo acumulativo e corretivo é a matriz natural pela qual se desenvolvem novas variedades de método experimental. Pois o método experimental não consiste de uma única e linear regra. Ele é multidimensional e multi-potencializado, adquirindo diferentes formas específicas através do uso em diferentes situações específicas e revelando novos poderes em cada novo caminho em que é usado. (RATNER, 1939, p. 56).

Para Ratner (1939), o método experimental rompia com a lógica linear de pensar racionalista ou empirista e criava uma matriz de investigação das situações problemáticas. Este processo investigativo se alimenta do acúmulo de significados gerados em cada experiência e, ao mesmo tempo, guia-se pelo princípio do falibilismo, que considera os significados acumulados como provisórios e hipotéticos, e não como certezas absolutas. A investigação experimental, reflexiva é mediada e mediadora de significados em continua reconstrução no processo de solução de situações problemáticas. O princípio falibilista se funda na crítica como condição da autocorreção dos significados, fomentando o crescimento e ampliação do processo investigativo. Este caminho mantém aberta as portas da investigação, contribuindo para a formação de um pesquisador guiado pela crítica. Por outro lado, é possível inferir que a formação humana centrada no acúmulo de conhecimento sem a crítica leva à rotina inerte ou ao fundamentalismo. Noutro extremo, a crítica sem o acúmulo do conhecimento leva ao imobilismo ou ao relativismo.

Ao abraçar o método experimental, Dewey abriu um campo vasto de investigações para a filosofia, uma vez que implicava em abandonar o campo seguro das verdades da metafísica e caminhar 
no terreno incerto da experiência, em um contexto de permanente mudança. A atitude experimental significou um deslocamento do fazer do filósofo para o campo comum da investigação dos problemas oriundos da própria vida. Desta forma, o filósofo se identifica como um ser humano entre os outros, um trabalhador entre outros trabalhadores, e seu campo de trabalho se constitui como um campo entre os outros, todos funcionando de forma inter-relacionada e interdependente entre si. O fazer filosófico adquire seu valor na medida em que se constitui um trabalho investigativo voltado para ampliar e transformar a experiência humana interconectada com uma diversidade de significados.

Considerando esta reorientação do fazer filosófico, Ratner identificou e classificou a amplitude do pragmatismo de Dewey em três círculos concêntricos:

A primeira área, em direção ao círculo interno, é ocupada pelo pensamento reflexivo, pela lógica, ou o que Dewey chama de investigação. Na segunda área estão os modos típicos da experiência humana, tais como o prático e o utilitário, a estética, a religião, ético-social, científico. A terceira área é aquela do mundo sociocultural, a sociedade nas suas formas organizadas e institucionais, o mundo que gera o que nós simplesmente e bastante corretamente chamamos de "questões sociais". (RATNER, 1939, p. 49-50, aspas do autor).

Em todas essas áreas Dewey fez prevalecer como objeto primário da investigação filosófica o campo contínuo, interconectado e complexo da experiência, que subentende as relações do organismo e meio que envolve dimensões como espaço e tempo, indivíduo e sociedade, natureza e cultura, pensamento e ação.

Dewey recorreu ao sentido etimológico da palavra Filosofia, como "amor à sabedoria", para diferenciá-la do entendimento de filosofia como conhecimento - um saber - a ser transmitido ou aplicado. O amor à sabedoria consiste na própria atividade de pensar os problemas que surgem na experiência e têm sempre um nível de universalidade que os integra à humanidade. Amor à sabedoria se converte em um amor à experiência como campo da vida.

Nesta perspectiva, a atividade da filosofia está intimamente ligada aos problemas culturais de cada época. Para ele, fundamentalmente, os problemas culturais vitais decidem os problemas filosóficos. Suas palavras são claras neste ponto: "Eu considero a filosofia de qualquer período como reflexo das maiores e mais profundas necessidades, conflitos, problemas e realizações culturais" (DEWEY, 1939, p. 522).

\section{O método genético: crítica e reconstrução da filosofia}

A análise deweyana sobre o papel da filosofia ganha destaque na obra Reconstrução em Filosofia, escrita em 1919, como resultado de conferências realizadas na Universidade Imperial do 
Japão. Em 1948, por ocasião de uma nova edição desta obra, Dewey, com 89 anos, escreveu uma nova introdução, em que enfatiza a relevância e atualidade deste trabalho, considerando o agravamento das condições gerais da humanidade devido às duas grandes Guerras Mundiais e reafirmando o postulado básico acerca do papel da filosofia:

[...] a função distinta da filosofia, seus problemas e campos de estudos decorrem das severas pressões e sobrecargas da vida da comunidade humana, em cujo seio surge certa forma de filosofia, e que, consequentemente, seus problemas específicos variam de acordo com as transformações por que constantemente passa a vida humana, que, às vezes, constituem uma crise e um ponto de reversão na história humana. (DEWEY, 1951, p. 8).

O autor enfatiza que a filosofia é sempre um fazer específico como forma de responder aos problemas, crises e transformações da comunidade humana. Neste sentido, o fazer da filosofia deve ser compreendido sob o ponto de vista histórico. Na obra que mencionamos, o autor emprega o método genético, uma possibilidade da matriz experimental, como meio mais eficaz para explicitar a origem das filosofias a partir dos elementos sociais e emotivos. Assim, o autor se contrapõe à concepção clássica que postulava a origem da filosofia a partir da razão, separada da experiência e voltada exclusivamente ao estudo sistemático do Ser Absoluto ou da Última e Absoluta realidade.

Um esclarecimento importante é fornecido por Schneider (1950) no seu reconhecido estudo da história da filosofia norte-americana, ao relacionar o método genético de que fala Dewey com a teoria evolucionista desenvolvida por Darwin. A explicação dada por Schneider mostra como o método genético significou um avanço indelével na maneira de fazer filosofia:

[...] a nova biologia trazia excelentes instrumentos de análise: "a adaptação ao meio", "a variação espontânea", "a luta pela existência", "o valor da sobrevivência", todos esses conceitos eram ao mesmo tempo teleológicos e físicos, que poderiam prontamente ser aplicados a todas as fases da cultura e à crítica de todas as instituições. O método genético ofereceu um programa [...] que transladou o centro do interesse evolucionista dos problemas da origem humana e dos planos divinos aos problemas da vida diária e da sociedade contemporânea. (SCHNEIDER, 1950, p. 368).

O estudo de Kaplan (2010) sobre a obra de Dewey nos fornece outra interpretação do método genético como característica da filosofia do pragmatismo: “[...] o pragmatismo aplica o método genético à filosofia, do mesmo modo que o aplica a outros campos do pensamento. As ideias devem ser compreendidas em termos de suas origens históricas e suas funções sociais, como já haviam enfatizado Marx e Nietzsche" (KAPLAN, 2010, p. 13).

O método genético exigia a reconstrução da filosofia, tarefa que requer investigação das causas e forças dos modos de pensar do homem, da origem de seus problemas e das consequências das soluções dadas para a vida humana, evidenciando a função social que ela exerce em cada tempo. A 
história da filosofia não pode ser apenas a história das ideias, mas a vinculação do pensamento filosófico com certo desenvolvimento da civilização na construção de determinada cultura do agir humano orientado por certa concepção de ser humano, da ética, da religião, da literatura, das instituições sociais, da política, entre outros. O método genético não é refutação lógica das teorizações filosóficas, mas clarifica a forma como ela tem se ocupado com valores incrustrados nas tradições sociais.

Amparado no método genético, Dewey iniciou sua análise demostrando que a razão primeira da origem da filosofia radica em uma capacidade distinta do ser humano, que consiste em reter as experiências passadas: ele é um ser “[...] capaz de recordar, reter e acumular experiências” (DEWEY, 1951, p. 29). Nos animais as experiências são acontecimentos fechados em si mesmos e se esgotam a cada ocorrência. Para o homem, cada experiência é povoada imaginativamente por outras experiências, que oferecem uma nuvem de pensamentos derivados de acontecimentos similares do passado: "O homem, porém, vive num mundo em que cada ocorrência é carregada de reminiscência e ressonâncias, em que cada acontecimento é lembrança de coisas passadas” (DEWEY, 1951, p. 29). Assim, o homem passa a ser governado pela memória, imaginação e comunicação, que lhe permitem fazer associações, sugestões e fantasias dramáticas de sua existência. A memória ofereceu um material primitivo, que, a partir de dois estágios, chegou a se tornar filosofia. Em primeiro lugar, certas experiências mais frequentes e multiplicadas em grupo, como as histórias ou manifestações emotivas, generalizam-se socialmente e consolidam-se:

Uma certa textura de tradições se consolida, a história se torna uma lembrança, possessão social, e a representação se eleva à classe dos ritos. A tradição assim formada vem a constituir uma espécie de modelo ao qual a fantasia individual e a inspiração se conformam. Construiu-se um diagrama permanente, ou melhor, um modelo duradouro de imaginação. Um modo comum de conceber a vida vem a criar-se e a fixar-se naquilo em que se instalam os indivíduos através da educação. [...] A poesia vem a fixar-se e a sistematizar-se. A história torna-se norma social. O drama original que restabelece uma experiência emocionalmente importante institui-se num culto. As sugestões outrora livres cristalizam-se em doutrinas. (DEWEY, 1951, p. 33$34)$.

O crescimento da vida social fez com que o imperativo político da jurisdição do poder sistematizasse, unificasse, centralizasse e consolidasse as tradições e crenças a fim de fortalecer o prestígio da autoridade: "Ao lado dessas acomodações e assimilações, que se originam do trato social e da necessidade de uma compreensão comum, há frequentemente um imperativo político que leva o poder a centralizar as tradições e as crenças a fim de ampliar e fortalecer o seu prestígio de autoridade" (DEWEY, 1951, p. 34). Foi o caso da Judeia, Grécia e Roma, que conseguiram sua unidade social e um poder político amplo em torno de cosmogonias, cosmologias e tradições éticas. 
Para Dewey, a generalização das ideias e crenças foi uma condição necessária, ainda que não suficiente, da origem da filosofia: “[...] sob influências sociais, tomou lugar uma fixação e organização de doutrinas e cultos que imprimiram traços gerais à imaginação e às regras gerais de conduta, e que tal consolidação foi um antecedente necessário à formação de qualquer filosofia, como compreendemos esse termo" (DEWEY, 1951, p. 34).

Paralelamente a esta constatação da apropriação do conhecimento para a legitimação do poder, Dewey analisa as brechas ou vias de constituição de um novo saber. Nesta perspectiva, a consolidação das tradições não impediu o desenvolvimento de um conhecimento positivo, voltado para resolver os problemas relativos às necessidades da vida de forma a corrigir as crenças, evitando a própria extinção da espécie. O surgimento da indústria, das artes e ofícios se deve a um conhecimento que resulta da observação de materiais e processos que proporcionam uma ação regular, contínua e exitosa em relação à sobrevivência, superando e questionando as explicações mágicas. Desenvolveu-se o hábito mental de experimentação desviando-se da regra do mero costume. O desenvolvimento das artes e ofícios no conhecimento da natureza foi se complexificando e avolumou o conjunto de conhecimentos precisos, exatos, verificáveis, de forma a colocar em conflito as crenças tradicionais, sentimentais e imaginativas. Para Dewey, os sofistas colocaram o conflito entre os dois tipos de crenças como questão central de suas ocupações, com efeito desconcertante sobre as crenças tradicionais e seu respectivo código moral. Sócrates também buscou a reconciliação deste conflito, mas, como ele abordou essa questão dando primazia às regras e critérios do método para tratar os fatos, colocando a dúvida, a controvérsia e a indagação como razões da vida de uma criatura racional, foi condenado à morte por desprezar os deuses e corromper a juventude. Estava posta uma nova necessidade para a filosofia: a crise gerada pela não aceitação do que é ditado pelo costume e pela autoridade política impunha a necessidade de buscar a justificação racional das crenças por meio do pensamento rigoroso e da demonstração rígida. Assim, a purificação racional da tradição serviu para a manutenção dos mesmos valores sociais e, consequentemente, da autoridade e do poder. Dewey interpretou o problema que se colocava e a solução, não menos problemática, dada pela filosofia:

Desenvolver um método de pesquisa racional e de prova que colocasse os elementos essenciais das crenças tradicionais numa base sólida; desenvolver um método de pensar e de conhecer que, ao mesmo tempo em que purificasse a tradição, lhe preservasse inalterados os valores morais e sociais; ou melhor, lhe acrescentasse, através dessa purificação, autoridade e poder. Em resumo, aquilo que repousava no costume haveria de ser restabelecido, não firmado nos hábitos do passado, mas sim na verdadeira metafísica do Ser e do Universo. A metafísica é um substituto do costume como fonte fiadora de elevados valores morais e sociais - este é o tema principal da filosofia clássica da Europa, tal como desenvolvida por Platão e Aristóteles - Filosofia que, recordemos, foi renovada e restaurada pela filosofia cristã da Europa medieval. 
Desta situação originou-se a constante tradição a respeito da função e papel da filosofia, que até recentemente tem controlado as filosofias sistemáticas e construtivas do mundo ocidental. (DEWEY, 1951, p. 39).

Dewey alerta que a filosofia não nasceu e se desenvolveu de "[...] modo imparcial e de origem franca e livre de preconceitos" (DEWEY, 1951, p. 40). O trabalho da filosofia consistiu em justificar, a partir de fundamentos racionais, o espírito das crenças passadas, ainda que não a forma da tradição associada à imaginação e à autoridade social.

Como vemos, Dewey mostrou como se dá a articulação do saber com o poder:

As crenças religiosas, bem como as poéticas, por se terem investido de funções e representarem valor social e político, passam à guarda das classes mais elevadas, diretamente associadas com os elementos dominantes da sociedade. Os operários e artífices, que possuem os conhecimentos práticos, prosaicos, tendem a ocupar uma posição social inferior, e aquela espécie de conhecimentos que possuem é afetada pelo mesmo menosprezo, pelo mesmo desapreço em que são tidos os operários manuais empenhados em atividades úteis ao corpo. (DEWEY, 1951, p. 36).

Esta hierarquização dos saberes adiou o desenvolvimento do método experimental, uma vez que a classe dos artífices foi colocada apenas um grau acima da dos escravos, fazendo com que seus conhecimentos e métodos fossem destituídos de prestígio e autoridade. Por sua vez, como a filosofia assume um lugar altaneiro, “[...] reclama para si a função de demonstrar a existência de uma realidade transcendental, absoluta ou oculta, bem como de revelar aos homens a natureza e as feições desta última e mais elevada realidade" (DEWEY, 1951, p. 43). A pretensão da filosofia é possuir um conhecimento mais elevado que o da ciência positiva e da experiência ordinária. Esta tendência culminou nos dualismos que analisaremos adiante.

Dewey colocou Francis Bacon como o precursor do espírito da vida moderna com seu aforismo: “conhecimento é poder." Bacon criticou o saber erudito como ocioso e inoperante. Sua investida contra a lógica clássica, inclusive na forma aristotélica, objetivava mostrar que estas se destinavam mais à demonstração e à persuasão do espírito, servindo ao conservantismo acrítico, do que à descoberta e conquista da natureza, promotoras do progresso. Nesta perspectiva, Bacon reconduziu a lógica para o campo da indução como possibilidade de fazer investigações capazes de penetrar nos segredos da natureza e descobrir fatos e princípios não conhecidos, num progresso continuamente renovado do conhecimento. Nesta lógica, as verdades poderiam ser vistas criticamente na medida em que poderiam ser provadas por novas experiências. Bacon viu na escola da natureza a fonte dos conhecimentos verdadeiros. A experimentação ativa seria o meio para o progresso contínuo, cumulativo e sistemático do conhecimento verdadeiro e para o domínio da natureza. Para Bacon, este domínio da natureza não deveria ser individual, mas coletivo. A este respeito, comenta Dewey: "A necessidade premente é a de 
uma organização cooperativa de investigações pela qual, em primeiro lugar, os homens possam aproximar-se da natureza coletivamente, e em segundo lugar, o trabalho da pesquisa possa ser levado a efeito de modo contínuo, de geração a geração.” (DEWEY, 1951, p. 51). A nova lógica gerou a revolução científica e industrial. Entretanto, segundo Dewey, a transformação que se deu no campo do conhecimento científico não foi acompanhada pela filosofia:

Esses quatro fatos, ciência natural, experimentação, controle e progresso, estão indissoluvelmente ligados uns aos outros. $\mathrm{O}$ fato de que até o presente a aplicação dos mais novos métodos e seus resultados tem influenciado os meios de vida, não os seus fins, ou melhor dizendo, o fato de que os ideais humanos têm sido, até aqui, afetados de um modo acidental, mais do que inteligente, significa, por enquanto, que a mudança tem sido técnica ao invés de humana e moral, econômica ao invés de adequadamente social. Usando a linguagem de Bacon, isto significa que enquanto nós temos sido razoavelmente bem-sucedidos na obtenção de um domínio sobre a natureza por meio da ciência, nossa ciência não é ainda capaz de fazer com que esse domínio seja sistemático e aplicado de forma preponderante em prol de um real alívio da situação do homem. Tais aplicações ocorrem, e ocorrem em grande número, mas elas são acidentais, esporádicas e externas. E esta limitação define o problema específico da reconstrução filosófica na atualidade, pois se torna enfática as deficiências sociais maiores que demandam diagnósticos inteligentes, bem como a criação e projeção de ideais e métodos. (DEWEY, 1951, p. 55-56).

Para Dewey, o aforismo baconiano falhou na medida em que tentou uma "expressão independente e emancipada" (DEWEY, 1951, p. 61). Culminou no individualismo econômico, político, epistêmico, religioso e moral. Um individualismo que buscou desvencilhar-se da razão universal que cria e constitui o mundo, deixando a mente submissa e complacente pela imposição de restrições, mas referendou a própria noção de razão, que passou a ser vista como se operasse na mente individual ou coletiva.

\section{A filosofia como instrumentalismo crítico aos dualismos}

O exposto acerca do método genético nos leva a firmar a convicção de que a atividade da filosofia não pode ser exercida no vácuo, ela deve tratar da forma como os conflitos se originam em cada tempo. Para o autor, o problema central do nosso tempo, do qual derivam os outros, é a conflitiva relação entre o desenvolvimento das ciências e os valores: "Seu problema central é a relação que existe entre as crenças sobre natureza das coisas devida à ciência natural e as crenças sobre valores" (DEWEY, 1939, p. 256).

Este problema tem alcance vital, porque requer ajuste das crenças elaboradas pela ciência e tecnologia, que se chocam com as crenças no campo dos valores e objetivos da conduta. Outro conflito 
central da filosofia ocidental é a defasagem que existe na luta entre as forças ativas do conhecimento científico e do poder da tecnologia e a dispersão gerada pelo atraso e a inércia dos hábitos e crenças. Resulta daí a necessidade da filosofia como atividade contínua de reconstrução das instituições, costumes, crenças de toda sorte para harmonizar ou ajustar com as potencialidades da ciência e tecnologia. Nesta perspectiva, a tarefa da filosofia é pensar reflexivamente "[...] o problema da relação da ciência física com as coisas da experiência comum” (DEWEY, 1939, p. 523). Assim, o pensar reflexivo pode romper com o isolamento entre a supremacia da experiência cognitiva como fonte de conhecimentos e a experiência comum, relegada a um status inferior e sem valor. Para o autor, é neste campo da experiência comum ou ordinária, na sua heterogeneidade e plenitude, que os problemas se originam e que os resultados da experiência cognitiva, reflexiva deveriam produzir seus frutos, transformando-a. Nesta perspectiva, Dewey entende haver uma relação instrumental cooperativa entre as duas dimensões experienciais: "Eu acredito que a conclusão de qualquer análise séria tornará o modo cognitivo intermediário entre um tipo mais antigo, menos organizado, mais confuso e fragmentado de conteúdo experienciado, e um outro mais esclarecido, mais livre, mais rico e sob melhor controle quanto à sua ocorrência." (DEWEY, 1939, p. 526).

Hickman (2001) destaca o princípio instrumentalista de Dewey e o caracteriza como "o filósofo da tecnologia". No entendimento de Hichman, Dewey trata a investigação como tecnologia, uma vez que usa instrumentos materiais e imateriais:

A chave para entender a obra de Dewey como uma contribuição à filosofia da tecnologia é, eu sugiro, uma valorização de sua afirmação de que toda investigação ou deliberação que envolve ferramentas e artefatos, sejam os instrumentos ou artefatos abstratos ou concretos, tangíveis ou intangíveis, deve ser vista como instrumental: em outras palavras, como tecnologia. (HICKMAN, 2001, p. 26).

O estudo sob este enfoque da "filosofia da tecnologia" de Dewey pode nos levar à discussão sobre a linguagem como instrumento ou tecnologia. $\mathrm{O}$ autor considera a linguagem como o “instrumento dos instrumentos” (DEWEY, 1958, p. 186). A análise da filosofia da linguagem na obra de Dewey abre um campo vasto para reflexão. O que queremos destacar aqui é a crítica que Dewey fez ao mostrar como a linguagem se transformou num poderoso instrumento da justificação do poder, questão já parcialmente discutida neste trabalho. Para Dewey, esta crítica da filosofia tem que enfrentar o problema dos dualismos, pois eles representam a criação e uso de uma linguagem como instrumento de dominação. Assim, trata-se de fazer a crítica ao dualismo gerado no campo da tradição filosófica entre o que foi estabelecido por uma determinada classe como conhecimento verdadeiro e, por isso, privilegiado em relação à experiência ordinária. Para Dewey, as filosofias tradicionais “[...] se 
desviaram do caminho pela falta de conectar seus resultados reflexivos com os assuntos da experiência do dia-a-dia" (DEWEY, 1958, p. 32).

$\mathrm{Na}$ análise deste pensador, as filosofias dualistas pressupõem a existência de uma "realidade" superior à precariedade e contingência da vida. Entrincheirada em concepções consideradas como valores absolutos, elas acusam a ciência como a culpada das mazelas da humanidade e da crise dos valores. Acusam também o senso comum de ser fonte de erros e desvios da verdade e perpetuação dos preconceitos. Ele mostrou a insustentabilidade das filosofias que se ocupam com a "busca da certeza" e propõe a filosofia experimental, que se guia pela contínua investigação a partir da experiência existencial, reconstruindo permanentemente os valores da experiência. Ele buscou as referências para desenvolver sua filosofia da experiência ou filosofia da natureza no "[...] reconhecimento do ponto de vista e conclusões científicas da biologia e antropologia cultural e da importação do método experimental de conhecer" (DEWEY, 1939, p. 524). A filosofia da experiência tem para o autor sua origem no campo da própria filosofia: “[...] minha técnica cresceu diretamente dos problemas das filosofias históricas" (DEWEY, 1939, p. 523).

Dewey tomou como pressuposto do naturalismo a mudança ininterrupta do mundo. Com este ponto de partida, sua filosofia buscou operar a síntese dos dualismos: eu e mundo, alma e corpo, natureza e Deus, inteligência e emoção, teoria e prática, objetivo e subjetivo, real e aparente, mental e físico, saber e fazer, espírito e corpo, trabalho e lazer. Para ele, os dualismos têm base social, ou seja, eles se originam numa sociedade dividia em classes doutas e classes trabalhadoras, ricos e pobres, nos que mandam e nos que são mandados. Os dualismos representam as rupturas sociais de continuidade e legitimam a continuidade dessa divisão de classes por meio da perpetuação de práticas autoritárias em todas as esferas da vida. Neste sentido, Dewey (1951, p. 118) criticou esta autoridade, que tutela o pensamento servindo-se do dualismo: "Onde quer que impere a autoridade, o pensamento é tido como duvidoso e nocivo." Neste sentido, a crítica aos dualismos é a crítica à cultura permeada pelos dualismos que perpassam todos os âmbitos da vida. A crítica ao dualismo é, mais especificamente, uma forma de crítica social e política.

Podemos depreender dessa vinculação da filosofia tradicional com estruturas sociais autoritárias a necessidade de uma revisão da própria prática filosófica: fazer a crítica sobre si mesma e, por decorrência, sobre a cultura. O filosofar sobre a filosofia passa a ser a reflexão sobre as próprias condições de produção da filosofia: "A filosofia repudia investigações sobre origens e finalidades absolutas a fim de explorar valores específicos e condições específicas de sua produção" (DEWEY, 1965, p. 13). Neste sentido, Dewey procurou resgatar a função da filosofia como reflexão experimental sobre os problemas que se originam do conflito gerado pelos dualismos em diversas áreas da vida, 
como a lógica ou epistemológica, social, ética e política, estética, educação, etc. A finalidade primeira da filosofia é pensar os problemas da vida: “[...] a filosofia deverá se tornar um método de localizar e interpretar os mais sérios dos conflitos que ocorrem na vida e um método de projetar meios para tratálos: um método de diagnóstico e prognóstico moral e político" (DEWEY, 1965, p. 18). Por ser uma filosofia da experiência, a sua especulação hipotética deve transformar a própria experiência: “[...] uma filosofia que tem a modesta pretensão de trabalhar para projetar hipóteses para a educação e a conduta da mente, individual e social, está, desse modo, sujeita a provar na prática as ideias que ela propõe" (DEWEY, 1965, p. 18). Na continuidade desse argumento, Dewey (1965, p. 18) enfatiza: “[...] o papel da filosofia futura é o de clarificar as ideias dos homens quanto aos embates sociais e morais de seus dias."

Nesta linha de raciocínio, Campbell (1995, p. 93) afirma acerca da filosofia crítica de Dewey: “[...] a crítica filosófica é uma tentativa persistente para descobrir e avaliar e, se necessário, substituir, os pressupostos básicos da cultura”.

Dewey criticou radicalmente a epistemologia característica da filosofia moderna porque ela adota os dualismos como pressuposto de suas construções teóricas, nas quais os conceitos de sujeito e objeto figuram como coisas separadas. Nesse caso, o conhecimento é tratado como posse de uma representação do mundo por uma mente individual pensante e independente do mundo externo. Dewey chamou esta filosofia de teoria expectadora do conhecimento, visto que toma a mente como um espelho da realidade, traduzindo-a numa imagem mental. O sujeito tem, assim, uma cópia da realidade. Este pressuposto resultou em filosofias da aceitação que se ocupam de descobrir uma realidade antecedente que fornece uma verdade como certeza logicamente demonstrada. Assim, essas filosofias transformam o que é encontrado na existência natural em "[...] um refúgio, um asilo de contemplação, ou um tema para elaborações dialéticas" (DEWEY, 1958, p. 51). Em contraponto a esta perspectiva, Dewey entende que a filosofia tem o papel de oferecer um controle inteligente, intencional à orientação da experiência.

Um problema implícito nas filosofias dualistas é o isolamento do indivíduo do mundo e dos outros, facilitando o desenvolvimento de uma autoridade externa de controle. Assim, subsiste uma ruptura de continuidade nas relações entre indivíduo e sociedade. Contrapondo-se a esta visão da filosofia clássica, Dewey entende que o agir humano se faz sempre num mundo público e comum. Por isso, coloca como base de todo o conhecimento a constituição social do eu:

O fato é que todo o indivíduo se desenvolveu e sempre deverá desenvolver-se em um meio social. Suas "respostas" tornam-se inteligentes ou adquirem significação simplesmente porque ele vive e age em um meio de significações e valores reconhecidos como tais. Pelo intercâmbio social, tomando parte em atividades que encarnam convicções, ele gradualmente adquire espírito próprio. A concepção de 
espírito como uma coisa isolada que o indivíduo possui está polarmente oposta à verdade. $\mathrm{O}$ indivíduo cria o espírito, desenvolve a mente na proporção em que o conhecimento das coisas se acha corporificado na vida que o cerca; o eu não é um espírito isolado a criar novos conhecimentos por sua conta própria. (DEWEY, 1979, p. $325)$.

Esta questão a respeito do indivíduo convida à discussão sobre a concepção de homem defendida por este filósofo. Ele concebe o homem como um ser social, como transparece no excerto anterior. Neste sentido, o homem deve ser compreendido na sua interdependência com o meio naturalsocial-cultural. O homem é naturalmente dotado de uma capacidade plástica, flexível, que lhe permite fazer variações em suas experiências e formar hábitos. O homem é um complexo de hábitos. Sua tese afirma: "Em verdade, o homem é criação do hábito, não da razão, tampouco do impulso" (DEWEY, 2002, p. 96). Plasticidade e interdependência são potencialidades do homem e constituem a imaturidade humana, condição de possibilidade para haver educação e crescimento durante toda da vida. Dewey é mordaz ao criticar a forma como a sociedade tem limitado este poder de crescimento, entulhando as novas gerações com o peso das tradições das gerações passadas:

As gerações novas mal têm solicitado acolhida, por assim dizer, no lar dos costumes dos adultos, muito menos sido convidadas para retificarem, através de uma melhor educação, as brutalidades e iniquidades cristalizadas nos hábitos. Cada geração moldase pela anterior, ou, quando não, introduz-se cegamente e furtivamente pelas brechas fortuitas que são deixadas. [...] a plasticidade tem sido corrompida e com as formas dóceis têm sido exploradas. $\mathrm{O}$ termo docilidade tem sido usado para significar não capacidade para aprender literalmente e generosamente, mas sim vontade tendente a aprender os costumes dos adultos, habilidade para aprender unicamente as cousas que aqueles investidos de autoridade desejam ensinar. Â capacidade primitiva de ensejar variações e modificações não se deu ainda oportunidade para agir como curadora de uma vida humana melhor. Ela tem sido oprimida pelas convenções, influenciada, desviada pelas conveniências dos adultos e praticamente reduzida a um simulacro de não afirmação de originalidade, a uma acomodação flexível do corpo de opiniões dos outros. Consequentemente, docilidade tem sido identificada com reprodução imitativa ao invés de ser considerada como tendo poder de reformar velhos hábitos, criá-los novamente. Plasticidade e originalidade têm sido colocadas em oposição uma à outra. A parte mais preciosa da plasticidade, a que constitui a habilidade de formar hábitos de julgamento independente e hábitos de iniciativa, engenho inventivo, tem sido ignorada. (DEWEY, 2002, p. 96-97).

Consideramos que esta crítica ao modo como as novas gerações são formadas na cultura ocidental justifica a dedicação de Dewey à investigação filosófica como forma de reconstruir o método a ser empregado para filosofar, ou seja, de reconstruir o método experimental por meio da análise do papel do pensar reflexivo. 


\section{Filosofia e pensamento reflexivo: investigação crítica e criativa}

A investigação filosófica acerca da lógica do pensar está ancorada no método genético que levou Dewey analisar o desenvolvimento histórico e social de como pensamos da, na e para a experiência. Parte desta análise vem sendo feita implicitamente na discussão anterior acerca da filosofia da experiência. Trataremos aqui de conceituar com mais precisão este termo. O pensamento reflexivo é definido como uma atividade que exige esforço consciente e voluntário para reconstruir os significados da experiência em uma situação problemática: "O pensamento reflexivo faz um ativo, prolongado e cuidadoso exame de toda crença ou espécie hipotética de conhecimento, exame efetuado à luz dos argumentos que a apoiam e das conclusões a que chega." (DEWEY, 1979a, p. 18, itálicos do autor).

Dewey identifica o pensamento reflexivo como a própria atividade da investigação, conforme podemos ver nesta definição: "A investigação é a transformação controlada ou dirigida de uma situação indeterminada em outra que é de tal modo determinada nas suas distinções e relações que a constituem que converte os elementos da situação original em um ‘todo’ unificado” (DEWEY, 1960, p. 104-105, grifos do autor). Pela investigação, a experiência problemática é transformada, permitindo a continuidade da vida. O pensamento reflexivo tem como função primeira o restabelecimento da continuidade da vida. A experiência é uma interação organismo-meio em um determinado contexto cujas conexões entre o agir pensando e o pensar agindo resultam na transformação do indivíduo e do meio, gerando acúmulo de significados naquele.

$\mathrm{Na}$ atividade reflexiva, a imaginação tem papel importante na condução da experiência e na criação de significados. Para o autor, a experiência é algo consciente, porque tem uma qualidade imaginativa na interação do ser vivo com o seu meio. Isto quer dizer que a experiência é permeada por significados derivados de experiências anteriores que interagem com aquilo que é problemático. Como afirmou o autor: "A imaginação é a única via pela qual esses significados podem chegar a uma interação atual; ou melhor, como acabamos de ver, o ajuste consciente entre o novo e o velho é a imaginação.” (DEWEY, 2010, p. 469). A imaginação é uma qualidade que está presente e faz a experiência ser humana, diferentemente de outras formas de vida: "A interação do ser vivo com o ambiente é encontrada na vida vegetal e animal, mas a experiência vivenciada só é humana e consciente à medida que aquilo que se dá no aqui e agora é ampliado por significados e valores extraídos do que está ausente na realidade e presente apenas na imaginação” (DEWEY, 2010, p. 469).

Ressaltamos que, segundo o autor, a lógica do pensamento não é uma forma lógica externa à experiência, um a priori extraído pela mente ou pelo pensamento, mas construída no próprio processo da investigação da experiência problemática. Acompanhemos o argumento do autor no excerto a seguir: 
[...] o pensamento não significa algum estado transcendental ou ato introduzido subitamente dentro de uma cena natural prévia, mas que as operações do conhecimento são respostas naturais do organismo, que constitui conhecimento em virtude da situação de dúvida na qual ele surge e em virtude do uso da investigação, reconstrução e controle sob o qual é colocado. (DEWEY, 1953, p. 332).

Assim, para ele, o objeto primário da investigação filosófica, a sua genuína habitação, é o campo contínuo, interconectado e conflituoso da experiência como acontecimento em que se dá a união orgânica do individual com o social. Nesse sentido, como analisamos, o filosofar se ocupa com a lógica do pensar e investiga as formas dessa lógica continuamente reconstruída no processo da reflexão sobre a experiência. A reconstrução da filosofia exige, por um lado, a crítica ao distanciamento da reflexão filosófica da experiência e, por outro lado, uma mudança copernicana da investigação filosófica na forma de pensamento reflexivo sobre os problemas éticos, políticos, lógicos, estéticos e educacionais desta mesma experiência, campo das possibilidades humanas.

Segundo Doll (1997), a reflexão é o veículo de transformação entre o processo e o produto. Para ele, o problema dos intérpretes de Dewey se deve ao fato de que “[...] muitas vezes não veem a reflexão como intermediário que liga a primazia da experiência prática com a experiência secundária da “investigação reflexiva continuada"” (DOLL, 1997, p. 155) Para Doll, Dewey criou uma nova epistemologia, na qual o conceito de reflexão somente se sustenta numa prática transformativa e recursiva:

[...] a reflexão é o veículo para preencher a lacuna que as filosofias passadas estabeleceram entre pensamento teórico e prático: o primeiro praticado apenas por aqueles formalmente treinados nos métodos especiais da filosofia; o último, pelas pessoas comuns na vida cotidiana da experiência humana. A reflexão toma a experiência e a examina criticamente, variadamente, publicamente: isto é, conecta as nossas experiências com as experiências dos outros, construindo uma rede de experiência em que o passado, presente e o futuro estão inter-relacionados. [...] ela é uma reconstrução das ações realizadas; é um exame dos significados criados. [...] É crucial que esta reflexão seja recursiva: que, uma vez realizada, seja uma orientação para novas práticas, que seriam em si mesmas uma ocasião para novas práticas. (DOLL, 1997, p. 157).

A análise da filosofia da experiência deweyana permite problematizar o impacto que a nuvem espessa da cientificidade ocasionou obnubilando a concepção de filosofia do autor, colocando-a como serva da ciência, criando, assim, confusão sobre o papel de ambas. Urge interpretar o pensamento deste autor captando o significado de filosofia como esta atitude reflexiva caracterizada pela criticidade que abarca as dimensões de totalidade, generalidade, radicalidade e criatividade diante dos acontecimentos que tecem a experiência. (DEWEY, 1979b). 
Nosso entendimento é que a reflexão, conceito basilar na reconstrução da filosofia proposta por Dewey, tem sua origem na própria filosofia, na análise lógica do processo da investigação, no pensar sobre como pensamos, inclusive na ciência. Por isso, a filosofia representa a atitude reflexiva diante deste conhecimento, procurando responder às suas exigências. O texto a seguir é muito esclarecedor desta questão:

É de vantagem identificar a filosofia com o ato de pensar enquanto distinta do conhecimento. O conhecimento, isto é, o conhecimento fundamentado, é ciência; ele representa as coisas que foram estabelecidas, ordenadas, dispostas racionalmente. Quanto ao ato de pensar, aplica-se a coisas em perspectivas. É ocasionado por uma incerteza e visa dissipar uma perturbação. Filosofia é pensar o que aquilo que é conhecido requer de nossa parte - qual a atitude de cor+respondência que ele exige. É uma ideia do que é possível, e não um registro de fatos consumados. Por essa razão é hipotética, assim como todo o ato de pensar. Ela assinala alguma coisa a ser feita alguma coisa a ser tentada. Seu valor não está em proporcionar soluções (o que só pode ser conseguido com a ação), e sim em analisar as dificuldades e sugerir métodos para nos havermos com elas. Pode-se quase definir a filosofia como o pensamento que se tornou consciente de si mesmo - que generalizou seu lugar, função e valor da experiência. (DEWEY, 1979b, p. 359).

Nesta perspectiva, à ciência cabe explicar os fatos deste mundo; à filosofia, pensar a atitude permanente e ativa diante das descobertas da ciência para manter a continuidade da vida. Para marcar essa diferença, demos voz ao autor: "Esta direta e íntima conexão da filosofia com uma visão de vida, a diferencia da ciência" (DEWEY, 1979b, p. 357). Para ele, a filosofia é uma atitude total diante da experiência atravessada pelos conflitos da vida, “[...] por existir a necessidade de integrar na ação os vários interesses em conflito" (DEWEY, 1979b, p. 359).

Quando os interesses emergem na experiência de maneira muito superficial, fundindo-se facilmente com a rotina e acomodações grosseiras, ou são insuficientemente organizados de forma a não são conflitarem entre si, a filosofia não se faz necessária ou se torna uma "fílosofia caseira". A filosofia como "amor à sabedoria" surge quando as contraposições ou embates de interesses que influem sobre a vida - ciência e religião, economia e ciência/estética; conservadorismo e liberdade; instituição e indivíduo - são motivo para reflexão e descoberta de alternativas mais compreensivas, que harmonizem os conflitos e restaurem a continuidade da experiência vivida na sociedade como um todo. Quando os ideais de conduta que atingem a toda a sociedade são muito diferentes e discrepantes entre si, instaura-se a necessidade da reflexão, que resulta nos sistemas filosóficos. A percepção do conflito de interesses coloca para o ser humano a incerteza sobre a direção da experiência, tornando necessária a atividade filosófica: "Se existem patentes incertezas na vida, as filosofias devem refletir essas incertezas" (DEWEY, 1979b, p. 360). 
A filosofia, concebida como investigação da experiência, busca exprimir os profundos conflitos e as infindas incertezas da civilização. Seu esforço é o de descobrir uma nova ordem de relações não patentes e fornecer novos significados, proporcionando claridade à própria experiência. Nessa perspectiva, a primeira tarefa da filosofia é assim colocada pelo autor: "Sua primeira incumbência é clarificar, emancipar e estender os bens inerentes às operações da experiência naturalmente originada" (DEWEY, 1958, p. 407). O pensamento reflexivo tem papel imprescindível na filosofia do porvir: “[...] o papel da filosofia futura é o de clarificar as ideias dos homens quanto aos embates sociais e morais de seus próprios dias. Seu objetivo será o de se tornar, tão humanamente quanto possível, um órgão com a função de cuidar desses conflitos" (DEWEY, 1951, p. 45). Por isso, ela tem amplo valor humano e libertador, na medida em que sugere direção inteligente à ação, à emoção e ao relacionamento social. Ao invés de perder-se na especulação contemplativa como um espectador que afastado da natureza aprecia as coisas absolutas em si, destinará a atividade inteligente para pensar a vida. Neste sentido, Dewey salienta a posição dissidente de William James, que afirmou que a “[...] 'filosofia é visão’ e sua principal função é libertar o espírito humano de preconceitos e propensões, bem como ampliar-lhe a concepção do mundo" (DEWEY, 1951, p. 42). Dewey se contrapõe também àquelas pretensões ambiciosas colocada para a filosofia: "Dizer, sem rebuços, que a filosofia nada oferece além de hipóteses e que estas hipóteses têm mérito somente quando tornam a mente do homem mais sensível à vida, parece igualmente uma negação da própria filosofia.” (DEWEY, 1951, p. 42).

Por outro lado, a experiência está saturada com classificações e interpretações produzidas pelas reflexões das gerações passadas, que parecem material fresco e ingenuamente empírico, mas são convencionalismos. São apelos ao preconceito e ao fanatismo (DEWEY, 1958, p. 33). Se mesmo desconhecendo as fontes e a autoridade de quem as produziu elas forem consideradas preconceitos, independentemente de serem verdadeiras ou falsas, a filosofia faz a crítica dos preconceitos. Assim, a outra tarefa da filosofia, em continuidade com a anterior, é a de detectar e refletir sobre os resultados das reflexões passadas que se encontram soldados aos materiais da experiência de primeira mão, ou seja, tornaram-se hábitos ou habituais conservando os preconceitos.

A filosofia desnuda intelectualmente os hábitos, os quais foram adquiridos na assimilação da cultura sem terem sido inspecionados criticamente, para ver do que são feitos e de que nos servem adotá-los, sem impedir o avanço inteligente da própria cultura. Caso contrário, eles frequentemente ofuscam e distorcem:

Uma filosofia empírica é, de qualquer modo, algo como despir-se intelectualmente. Não podemos nos despojar permanentemente dos hábitos intelectuais que contraímos e vestimos quando assimilamos a cultura de nosso tempo e de nosso lugar. Mas o progresso inteligente da cultura exige que abandonemos alguns desses hábitos, que os 
inspecionemos criticamente, a fim de descobrir sua constituição e seu uso para nós. Não podemos retornar à primitiva ingenuidade. Não obstante há uma ingenuidade cultivada dos olhos, dos ouvidos e do pensamento, a qual é atingível, mas só pode ser adquirida através da disciplina de um pensamento rigoroso. (DEWEY, 1958, p. 37).

A "disciplina de um pensamento rigoroso" denota a tarefa crítica da filosofia diante do conhecimento de seu tempo e espaço: “[...] objetiva a crítica das crenças, instituições, costumes e da política com respeito a seu significado sobre o bem" (DEWEY, 1958, p. 408). Desta forma, a crítica aos preconceitos significa para Dewey "[...] clarificação e emancipação, quando eles são detectados e atirados fora” (DEWEY, 1958, p. 37). Podemos concluir o raciocínio do autor na defesa da filosofia como atividade crítica capaz de desenvolver métodos críticos: “[...] filosofia como um método crítico de desenvolvimento de métodos de crítica" (DEWEY, 1958, p. 408). Assim captada, a filosofia se caracteriza por uma matriz de pensamento crítico.

Dewey concebe a filosofia como inerentemente crítica, entendendo que ela tem uma posição distinta entre os vários modos de crítica em geral: ela é a crítica da crítica. A necessidade da crítica advém da tendência dos objetos se tornarem rígidos, compartimentos não comunicativos e, portanto, não interativos. Dewey menciona a variedade de especializações como a ciência, a indústria, a política, a religião, a arte, a educação, a moral, etc., que, quando se institucionalizam ou profissionalizam, isolam-se e petrificam-se. Daí a necessidade da tarefa crítica da filosofia numa prática comunicativa:

A superespecialização e a divisão dos interesses, as ocupações e os bens criam a necessidade de um meio geral de intercomunicação, de uma crítica mútua em torno da tradução de uma região ilhada da experiência à outra. Assim, como um órgão de crítica, a filosofia resulta, com efeito, um mensageiro, um oficial de conexão, fazendo reciprocamente inteligíveis as vozes que falam línguas provincianas, e desta forma, ampliando e retificando as significações de que estão grávidas. (DEWEY, 1958, p. 410).

Este meio de intercomunicação em que se exercem a investigação, a crítica mútua, a inteligibilidade das significações traz a necessidade de compreender a íntima relação da filosofia com a democracia.

\section{Filosofia, democracia e educação}

Em 2016 foi comemorado o centenário da obra de Dewey intitulada Democracia e Educação. Esta obra tem o seguinte subtítulo: Introdução à Filosofia da Educação. Neste trabalho Dewey analisa a articulação entre filosofia, democracia e educação. O ponto de articulação é a filosofia da experiência, 
que pode ser denominada como filosofia da experiência reflexiva ou filosofia da experiência democrática.

Dewey explicitada sua concepção de democracia da seguinte forma: "Uma democracia é mais do que uma forma de governo; é, essencialmente, uma forma de vida associada, de experiência conjunta e mutuamente comunicada" (DEWEY, 1979, p. 93). Nesta definição, a democracia se traduz numa forma reflexiva de cooperação em comunidade. Dewey critica os reducionismos em que a democracia pode ser enredada:

A democracia não pode ser concebida como algo inerente a alguma seita ou raça, tampouco como alguma apoteótica forma de governo já sancionada e consagrada. É tão só um nome a identificar a verdade segundo a qual a natureza humana se desenvolve somente quando seus elementos tomam parte na direção das coisas que são comuns, sociais. Coisas pelas quais homens e mulheres formam agrupamentos familiares, sociedades comerciais, governos, igrejas, associações científicas, etc. [...] A identificação da democracia com democracia política, identificação essa que, digamos de passagem, é responsável pela maioria de seus malogros, baseiam-se nas ideias tradicionais que fazem do indivíduo e do Estado entidades preexistentes em si mesmas. (DEWEY, 1951, p. 162).

O autor definiu a democracia como uma das condições para a educação atingir os objetivos da formação cultural e da eficiência social, no sentido de continuidade da vida da sociedade. A separação destes dois objetivos é própria de sociedades aristocráticas, que oferecem educação distinta para os membros superiores, as elites, e outra para os membros inferiores, as massas. Cultura não deve ser tomada como coisa exclusivamente interior, mas sim como o desenvolvimento completo da personalidade, da sua incomensurabilidade humana, permitindo a todos participar livre e plenamente das atividades comuns numa experiência valiosa em extensão, profundidade e contínua expansão e crescimento. Neste sentido, o autor mostra a articulação dos conceitos de educação e democracia:

Mas se a democracia tem significação moral e ideal, é porque exige de todos uma retribuição social e porque proporciona, a todos, oportunidade para o desenvolvimento das suas aptidões distintivas. O divórcio dos dois objetivos na educação é fatal à democracia; a adoção da significação mais restrita de eficiência priva-a de sua justificação essencial (DEWEY, 1979b, p. 133).

Isto nos leva a pensar que o ensino que se ocupa de selecionar (considere-se as avaliações, vestibulares, etc.) e formar os mais dotados não é democrático. Como diz Reboul, “[...] a tarefa primeira de um ensino democrático é ocupar-se com os alunos menos dotados; é no nível desses alunos que se medirá o êxito, ou o malogro, desse ensino" (REBOUL, 1974, p. 99).

Para Cochran (2011), Dewey acreditava que a próxima revolução científica aconteceria quando o ser humano aplicasse seus conhecimentos para pensar os problemas sociais. Neste sentido, a democracia deweyana é uma visão do público em que as comunidades democráticas são comunidades 
epistêmicas, lócus de produção dos conhecimentos necessários para que os indivíduos construam um mundo mais significativo para eles mesmos a partir das necessidades partilhadas em circunstâncias comuns. Outro aspecto pertinente da comunidade democrática como comunidade investigativa é o de ser ela uma comunidade ética promotora da liberdade e crescimento das pessoas. Suas considerações são: “[...] a ciência e a investigação sobre o controle democrático da organização social compartilham destas virtudes: uma atitude experimental, criatividade, consulta cooperativa com os outros, a abertura à diferença e uma vontade de rever os próprios pontos de vista” (COCHRAN, 2011, p. 326).

No entendimento de Bernstein (2011, p. 303), a concepção deweyana de democracia pressupõe uma cultura democrática: "Democracia requer uma robusta cultura democrática na qual as atitudes, emoções e hábitos que constituem o ethos democrático estejam incorporadas." Este ethos pressupõe o desenvolvimento de uma "inteligência social", clarificando que inteligência se diferencia de razão como faculdade suprema do juízo. Para o autor, o sentido de inteligência deweyana implica entender que

Inteligência não é uma faculdade; ela é um conjunto de disposições que envolve a imaginação, sensibilidade para com a complexidade das situações concretas, capacidade de ouvir as opiniões dos outros e uma atitude experimental falibilista na solução dos problemas. Inteligência envolve um compromisso apaixonado com os finsem-vista que alguém procura alcançar e uma vontade de aprender com os próprios erros. (BERNSTEIN, 2011, 304).

Segundo Amaral (1990), o método da inteligência é o método da democracia. A sociedade democrática é a única capaz de permitir a livre e necessária comunicação entre os indivíduos, a ação compartilhada, a cooperação, a experiência inteligente. A sociedade democrática é o espelho do próprio organismo humano. Para sobreviverem, os homens têm que estar em contínua interação com o ambiente (escala biológica) e, para continuar vivendo como seres humanos, no ambiente específico do social, precisam manter-se em comunicação com os outros homens, isto é, precisam se associar e cooperar com os demais. "Sobrevivência humana significa sobrevivência social, e esta significa ação, fruto do pensamento inteligente do homem.” (AMARAL, 1990, p. 68). A própria inteligência tem origem na cooperação social. Por isso, a filosofia não pode manter-se isolada da experiência humana, dos problemas reais da vida, diante da avalanche das transformações. Então, a autora analisa o papel da filosofia no pensamento deweyano da seguinte forma:

[...] podemos entender o papel que Dewey efetivamente atribui à filosofia, isto é, de ser um método de resolver os problemas do homem em suas relações com as condições reais da vida presente. Afinal, esses problemas dizem respeito, como sabemos, à necessidade de conciliar as suas crenças sobre os valores que devem dirigir sua conduta. Então, se ela é um agente de enlace entre as conclusões da ciência e os modos de ação social e pessoal, ela pode excepcionalmente pretender alcançar graus mais 
elevados de generalização para os resultados da ciência. Isso porque, na verdade, esses nada mais são do que crenças, conforme procuramos salientar, e sua generalização em grau mais alto limita-se à sua aplicação ao campo das relações sociais. (AMARAL, 1990, p. 112).

Segundo Cunha, a filosofia tem função civilizadora na medida em que o pensamento reflexivo se constitui no instrumento para prover formas de comportamento que lhe permitam enfrentar as situações problemáticas. Esta função se sustenta na crença democrática:

A função civilizadora da filosofia reflete a crença sustentada por Dewey na sociedade democrática enquanto possuidora da capacidade de absorver as mudanças que se processam em suas instituições. [...] A visão deweyana das tarefas da filosofia implica uma crença na reconstrução dos valores correntes enquanto processo partilhado por todos; somente por meio da ação cooperativa, sob a orientação da inteligência, pode-se controlar o ambiente físico e social com o intuito de torná-lo mais adequado à vida humana. (CUNHA, 1994, p. 34-35).

Para Dewey, a formação dos hábitos filosóficos e atitudes democráticas é mediada pela educação. O valor humano da educação consiste no fato de ela ser o meio de proporcionar a todos a possibilidade de se aquinhoarem dos benefícios sociais e desenvolverem suas aptidões individuais, e também exige de todos a respectiva retribuição social. Para Dewey, a educação deve propiciar um ambiente favorável para que cada indivíduo tenha a possibilidade de desenvolver sua natureza potencialmente social. Da mesma forma, a reflexão da filosofia sobre as necessidades humanas na luta pela sobrevivência deve ser regida pelos fins e valores democráticos, para a garantia e ampliação desses fins e valores. Isto significa que a presença da filosofia torna-se necessária para uma educação integral como formação na e para a democracia. Podemos depreender das seguintes palavras do autor que a educação filosófica é condição sine qua non para a democracia:

A melhor garantia de obter eficiência e poder coletivos está na liberação e no uso das variadas capacidades individuais de iniciativa, planejamento, previsão, vigor e paciência. A personalidade há de ser educada, e a personalidade não pode ser educada caso lhe confinemos as exteriorizações, as realizações, a coisas técnicas e especializadas, ou às relações menos importantes da vida. A educação integral é levada a efeito somente quando existe, da parte de cada pessoa, um quinhão de responsabilidade proporcional às respectivas capacidades, pela formação de ideais e planos de ação dos grupos sociais. Este fato fixa a importância da democracia. (DEWEY, 1951, p. 162).

A concepção de educação deweyana tem o pensar como princípio da aprendizagem. Pensar é o princípio educativo para Dewey: “[...] é evidente que a educação, quanto a seu lado intelectual, está vitalmente relacionada com o cultivo da atitude do pensar reflexivo, preservando-o, onde já existe, e substituindo os métodos de pensar mais livres por outros mais restritos, sempre que possível" (DEWEY, 1979a, p. 85, itálicos do autor). Com pequenos acréscimos, ele declara: “[...] a educação 
consiste na formação de hábitos de pensar despertos, cuidadosos, meticulosos” (DEWEY, 1979a, p. 86, itálicos do autor).

Cabe ainda observar que a liberdade se origina e cresce com a formação contínua de hábitos reflexivos, como processo ativo, que demanda a atividade educativa. Liberdade é o poder de ação e transformação engendradas no processo reflexivo: “[...] liberdade é poder de agir e executar independentemente de tutela exterior. Significa domínio, capaz de exercício independente, emancipado dos cordéis da direção alheia, não simplesmente atividade exterior sem peias” (DEWEY, 1979b, p. 93). A liberdade como poder do pensamento reflexivo é a essência da democracia.

Dewey critica o conceito de liberdade forjado pelo liberalismo e pelo desenvolvimento da ciência e da indústria, que glorifica uma liberdade geral distante da vida prática das pessoas. $\mathrm{O}$ atributo da liberdade é o individualismo, pertence à esfera do privado mais do que do público. Dewey é enfático em afirmar a "eclipse do público" (DEWEY, 1991). Nesta perspectiva, apreciamos o interesse de Dewey pela educação como uma prática democrática que desenvolva a sensibilidade pelas injustiças sociais e que se empenhem, como ele mesmo o fez em sua vida, em práticas de transformação destas mesmas situações.

A educação como a aprendizagem de hábitos de reflexão pode ser entendida como "aprender é aprender a pensar". (DEWEY, 1979b p. 83.) Aprender a pensar é aprender a aprender, no sentido de aprender como construir ou produzir os conceitos, conhecimentos ou significações, que aumentam a eficiência na ação e ampliam a capacidade de aprender mais coisas sobre nós e o mundo em que vivemos, em novas situações, constituindo uma experiência inteligente ou reflexiva. Outra consequência que podemos tirar desta fórmula é que pensar é o método de aprender: "Pensar é o método de se aprender inteligentemente, de aprender aquilo que utiliza e recompensa o espírito" (DEWEY, 1979b, p. 168-169). Pensar incorpora nessa formulação os sentidos explicitados sobre as tarefas da filosofia.

A filosofia, nesta matriz reflexiva, é em si mesma formadora do humano, que requer a educação de si numa vida democrática. Neste sentido, a filosofia pode ser entendida como uma forma de vida, especialmente porque, como o próprio autor reconhece, a filosofia como "amor à sabedoria" indica uma prática moral, assim como a democracia. Sabedoria é um termo moral, pois se refere a uma atitude de liberdade e deliberação crítica e criativa, um ato de escolha, uma preferência por uma forma de vida melhor que outras. A democracia, sustentada pelo pensamento reflexivo, é o lócus da deliberação, da crítica, da criação de possibilidades e instrumentos na busca por uma vida humana com dignidade, justiça e beleza. É a escolha de um caminho que permite escolhas. A vida democrática e humana é aquela que resulta do pensamento reflexivo exercitado numa comunidade investigativa que respeita e 
promove o crescimento de seus membros e evita toda forma de exclusão. Por isso, desvincular a educação da filosofia e da democracia é fatal para a formação humana numa comunidade comprometida com o crescimento humano. E a defesa do autor é democratizar a filosofia, ou mostrar que a filosofia é parte integrante da vida democrática, porque é indispensável para a formação da pessoa capaz de participar de forma simpática da solução dos conflitos comuns, de desenvolver sua autonomia e de se envolver nas práticas solidárias. Daí sua visão de pessoa: "Somos como pessoas aquilo que nós mostramos ser quando associados a outras pessoas, numa livre reciprocidade de dar e receber" (DEWEY, 1979, p. 133).

O entendimento da filosofia como atividade de pensamento numa comunidade crítica, criativa e cooperativa, que opera com a reflexão por dentro da experiência, germinando-a de significação num processo contínuo e interativo, permitiu a Dewey conceber a íntima relação entre filosofia e educação. Contrapondo-se à prática de aplicar filosofias, ou seja, “ideias já feitas” à educação, a filosofia passa a exercer seu papel ao pensar os problemas da educação como problemas da vida. Por isso, para o autor, a filosofia é

[...] uma formulação explícita dos problemas da formação de uma mentalidade reta e de bons hábitos morais, tendo-se em vista as dificuldades da vida social contemporânea. A mais profunda definição de filosofia que se possa dar é a de ser a teoria da educação em seus aspectos mais gerais. (DEWEY, 1979b, p. 364).

Entendemos que a formação desta "mentalidade reta e [de] bons hábitos morais" se dá no processo reflexivo, dialógico, ou seja, numa comunidade de vida democrática. Isto nos leva a entender a teoria deweyana do pensamento reflexivo, que é uma teoria do processo de educar, como eminentemente filosófica. Assim, a filosofia da experiência é a filosofia da educação: “[...] a tarefa da educação poderia ser definida como emancipação e alargamento da experiência” (DEWEY, 1979a, p. 199). Mantendo a coerência deste raciocínio, Dewey define educação desta forma: “[...] é uma reconstrução ou reorganização da experiência, que esclarece e aumenta o sentido desta, e também, a nossa aptidão para dirigir o curso das experiências subsequentes" (DEWEY, 1979a, p. 83, grifos do autor). Da mesma forma, o método de educar é o pensar capaz de transformar a realidade, iniciando, desenvolvendo e ampliando a órbita de significados da experiência humana associada, compartilhada, livremente comunicada.

Assim a filosofia da educação somente pode ser operada numa filosofia da democracia, numa escola de experiência democrática. Neste sentido, podemos entender que, para Dewey, o professor reflexivo não pode abrir mão de um fazer filosófico na reconstrução da experiência criando novos hábitos, condição para cada um ser educador de si na comunidade democrática. A comunidade 
democrática é educadora para além dos espaços da escola e nela todos têm oportunidade de pensar sua formação, constituindo um meio e um fim da educação.

\section{REFERÊNCIAS}

AMARAL, Maria N. C. Pacheco. 1990. Dewey: Filosofia e experiência democrática. São Paulo: Perspectiva/EDUSP.

BERNSTEIN, Richard J. Dewey's vision of radical democracy. In: COCHRAN, Molly (Ed.). The Cambridge companion to Dewey. New York: Cambridge University Press, 2011, p. 288-308.

CAMPBELL, James. Understanding John Dewey: nature and cooperative intelligence Carbondale: Southern Illinois University, 1996.

COCHRAN, Molly, Dewey as an international thinker. In: COCHRAN, Molly (Ed.). The Cambridge companion to Dewey. New York: Cambridge University Press, 2011. p. 309-336.

CUNHA, Marcus Vinicius da. John Dewey: Uma filosofia para educadores em sala de aula. Petrópolis: Vozes. 1994.

DEWEY, John. A arte como experiência. Tradução: Vera Ribeiro. São Paulo: Martins Fontes, 2010.

. Human nature and conduct. New York: Prometheus Book, 2002.

. Como pensamos: como se relaciona o pensamento reflexivo com o processo educativo: uma reexposição. Tradução: Haydée Camargo Campos. 4. ed. São Paulo: Nacional, 1979a. Atualidades pedagógicas, vol. 2.

. Democracia e educação. Tradução: Godofredo Rangel e Anísio Teixeira. São Paulo: Nacional, 1979b. Atualidades pedagógicas; vol. 21.

. Essays in experimental logic. New York: Dover, 1953.

Experience and nature. New York: Dover, 1958.

. Experience, knowledge and value. In: SCHILPP, Paul A. (Ed.) The Philosophy of John Dewey, Chicago: Northwestern University, 1939. p. 515-608.

. Logic. The theory of inquiry. New York: Henry Hold and Company, 1960.

Reconstruction in philosophy. New York: Mentor Books, 1951.

. The influence of Darwin on Philosophy and other Essays in contemporary Thought. Bloomington: Indiana University Press, 1965.

. The public and its problems. 12. ed. Ohio: Ohio University Press, 1991. 
. The quest for certainty: a study of the relation of knowledge and action. 12. ed., New York: Minton, Balch \& Company, 1929.

DOLL JR., William E. Currículo: uma perspectiva pós-moderna. Tradução: Maria Adriana Veríssimo Veronese. Porto Alegre: Artes Médicas, 1997.

HICKMAN, Larry A. Phylosophical tools for technological culture: putting Pragmatism to work. Bloomington: Indiana University Press, 2001.

KAPLAN, Abraham, Introdução. In: DEWEY, John. A arte como experiência. Tradução: Vera Ribeiro. São Paulo: Martins Fontes, 2010.

REBOUL, Olivier. Filosofia da educação. Tradução: Luiz Damasco Penna e J. B. Damasco Penna. São Paulo: USP, 1974. 
Philosophy of experience and human formation for John Dewey

\begin{abstract}
:
The objective of this study is to investigate the conception of philosophy and its relation to human formation in the thinking of John Dewey. The work aimed at analyzing the concepts in the main works of the author and his interpreters. The paper analyzes the reconstruction of philosophy as a philosophy of experience anchored in the genetic, experimental, reflexive, critical and creative method. The philosophy of experience is opposed to the dualisms and the spectator philosophies of knowledge that maintains the social division into classes. The role of the philosophy of experience is to rationalize through inquiry the possibilities of human experience through the critical reconstruction of the meanings. The philosophy of experience is a condition of possibility for democratic life and for an education based on freedom and human emancipation.
\end{abstract}

Key-words: Philosophy. Human formation. John Dewey.

\section{Darcísio Natal Muraro}

E-mail: murarodnm@gmail.com
Filosofía de la experiencia y formación humana para John Dewey

\section{Resumen:}

El objetivo de este estudio es investigar la concepción de filosofía y su relación con la formación humana en el pensamiento de John Dewey. El estudio tuvo como objetivo comprender los principales conceptos en la obra del autor y sus intérpretes. El artículo analiza la reconstrucción de la filosofía como filosofía de la experiencia anclado en el método genético, experimental, reflexivo, crítico y creativo. La filosofía de la experiencia se opone a los dualismos y a las filosofías espectadoras del conocimiento que mantiene la división social en clases. El papel de la filosofía de la experiencia es racionalizar, mediante la investigación, de las posibilidades de la experiencia humana a través de la reconstrucción crítica de los significados. La filosofía de la experiencia es condición de posibilidad de la vida democrática y una educación guiada por la libertad y la emancipación humana.

Palabras clave: Filosofía. Formación humana. John Dewey.

Enviado em: 18/08/2014

Versão final recebida em: 31/01/2017

Aprovado em: 16/02/2017 